OPEN ACCESS

Edited by:

Mariagrazia Di Giuseppe, University of Pisa, Italy

Reviewed by:

David Kealy,

University of British Columbia, Canada Vera Békés,

Yeshiva University, United States

*Correspondence:

Leonie Kampe

I.kampe@phb.de

Specialty section:

This article was submitted to

Psychopathology,

a section of the journa

Frontiers in Psychiatry

Received: 31 January 2021

Accepted: 06 April 2021

Published: 11 June 2021

Citation:

Kampe L, Bohn J, Remmers C and Hörz-Sagstetter S (2021) It's Not That

Great Anymore: The Central Role of Defense Mechanisms in Grandiose and Vulnerable Narcissism.

Front. Psychiatry 12:661948. doi: 10.3389/fpsyt.2021.661948

\section{It's Not That Great Anymore: The Central Role of Defense Mechanisms in Grandiose and Vulnerable Narcissism}

\author{
Leonie Kampe ${ }^{1,2 *}$, Johannes Bohn ${ }^{3}$, Carina Remmers ${ }^{4}$ and Susanne Hörz-Sagstetter ${ }^{1}$ \\ ${ }^{1}$ Department of Clinical Psychology and Psychotherapy, Psychologische Hochschule Berlin, Berlin, Germany, ${ }^{2}$ Department \\ of Psychiatry, Psychotherapy and Psychosomatic Medicine, Psychosoziales Zentrum Itzehoe, Itzehoe, Germany, \\ ${ }^{3}$ Department of Education and Psychology, Freie Universität Berlin, Berlin, Germany, ${ }^{4}$ Faculty of Health/School of \\ Psychology and Psychiatry, Witten/Herdecke University, Witten, Germany
}

Objectives: The concept of narcissism contains a yet unresolved paradox: Its grandiose facet depicts the psychopathological core but is often associated with life-satisfaction and overall functioning, whereas its vulnerable facet is associated with psychological distress, but still not included in the international classification systems. Our goal was to investigate the relationship between the two facets of narcissism expecting underlying defense mechanisms to be core elements. First, we aimed to identify defense mechanisms specific to grandiose and vulnerable narcissism. Second, we explored how both facets are differentially associated with psychological distress, assuming that grandiose narcissism would be associated with less psychological distress than vulnerable narcissism. Third, we investigated the mediating role of defense mechanisms between narcissism and psychological distress.

Methods: In a non-clinical sample of $N=254$ individuals, the Pathological Narcissism Inventory was used for the assessment of grandiose and vulnerable facets of narcissism, the Defense Style Questionnaire for defense mechanisms, and the Brief Symptom Inventory for psychological distress. Structural equation modeling was employed to identify distinct factors of grandiose and vulnerable narcissism. Associations between specific defense mechanisms and both facets were calculated. Furthermore, the direct association between both facets and psychological distress was examined. We finally explored whether defense mechanisms mediate the association between distress and both grandiose and vulnerable narcissism.

Results: A distinct pattern of defense mechanisms for each facet of narcissism could be extracted: Both facets showed significant positive correlations with specific intermediate and all maladaptive defense mechanisms. Only grandiose narcissism showed significant positive correlations with adaptive defenses. Vulnerable narcissism showed negative correlations with all adaptive defenses. Specifically, grandiose narcissism was significantly related to anticipation, pseudo-altruism, rationalization, and dissociation, whereas vulnerable narcissism was negatively related to all these defense mechanisms. While grandiose narcissism was not related to psychological distress, vulnerable narcissism showed high correlations with psychological distress. Intriguingly, 
mediator analysis found that grandiose narcissism was related to psychological distress when mediated by maladaptive defense mechanisms.

Discussion: The role of defense mechanisms is central for a differentiated understanding of the two different faces of narcissism. The relevance of assessing defense mechanisms in clinical settings, and related empirical findings are discussed.

Keywords: grandiose narcissism, vulnerable narcissism, defense mechanisms, psychological distress, personality, emotion regulation, adaptive functioning, dimensional assessment

\section{INTRODUCTION}

The concept of narcissism plays a central role in personality research as well as in clinical psychological practice. Due to the seemingly contradicting manifestations of narcissism, understanding the underlying mechanisms is of both theoretical and practical importance. On the one hand, narcissism, as a personality trait, is related to numerous positive factors such as socio-economic success, overall life satisfaction, as well as psychological health $(1,2)$. On the other hand, high expressions on the continuum of narcissism are associated with proneness to emotional crisis, attachment anxieties, problematic long-term relationships, and severe problems in psychotherapy such as emotional reticence, unwillingness to change, and a higher dropout rate (3-6).

Especially in clinical diagnostic settings, narcissistic pathology is often overlooked, and treatments are classified as seemingly "going well." Eventually, when confronted with unexpected dropout, crises about upcoming separations from the therapist, or when patients change only little over the course of the treatment $(7,8)$, the underlying vulnerability and dysfunctionality of narcissism becomes evident. Many controversies surrounding the concept of narcissism and its clinical manifestations may be rooted in its one-sided operationalization in the international classification systems (9-11). The current definition of pathological narcissism in DSM-5 predominantly relates to the grandiose manifestation, consisting of a sense of entitlement, an excessive need for admiration, arrogant and self-centered behaviors, a proneness to envy and devaluation of others, and a lack of empathy and exploitative behaviors (12). Emerging consensus criticizes this definition by calling out its conceptual narrowness. Specifically, the definition of narcissism in DSM-5 neglects a different, more vulnerable side of this phenomenon $(9,13,14)$. Psychoanalytic theory, empirical evidence, and clinical manifestations point to another facet of narcissism that captures specific insecurities underlying grandiose manifestations $(15,16)$. Following this theory, grandiose narcissism is understood as a defensive shield that is rigidly and unconsciously built up to defend the conscious ego from threats to the self-esteem (17). This theoretical conceptualization helps to understand why grandiose narcissism operates as a defensive structure that is related to indicators of psychological health, whereas its underlying vulnerability is not. By calling it a character defense, the defensive structure of grandiose narcissism may itself be seen as the core of the narcissistic pathology. Following this line of thought, it becomes essential to address defense mechanisms in psychotherapeutic treatment in order to access underlying vulnerabilities and their related psychological problems (17).

In spite of its clinical vividness, this complex psychoanalytic relationship has not yet been fully investigated empirically. To fill this gap, the current study has the goal to investigate the quality and functional role of defense mechanisms in grandiose and vulnerable manifestations of narcissism and their associations with the experience of psychological distress.

\section{Defense Mechanisms}

The idea that specific manifestations of narcissism are related to a distinctive defensive structure has been thoroughly elaborated in psychoanalytic literature $(17,18)$. Defense mechanisms are conceptualized as unconscious mental operations that regulate internal and external conflicts implicitly $(19,111)$. Defense mechanisms that are assumed to play a central role in narcissism are related to severe anxieties (20) and shame (21). With regard to their functionality, defense mechanisms can be clustered hierarchically and spanned over a continuum ranging from adaptive, over intermediate (neurotic), to maladaptive (pathological) mechanisms (22). Adaptive defense mechanisms such as humor, anticipation, and suppression help the individual to deal with unpleasant emotional experiences such as ambivalences or distressing realities. They can be used flexibly and reduce negative affective responses successfully. For example, in a situation in which a person embarrasses herself, she may circumvent the aversive feeling of being ashamed by making a joke. Adaptive defenses are related to psychological health and negatively associated with personality pathology (22). Intermediate (or in psychoanalytic terms: neurotic) defenses are also unconsciously applied to regulate emotional distress. Unlike adaptive defenses, they are used more rigidly and aim to avoid the experience of upsetting emotions. One of the functions of intermediate/neurotic defense mechanisms can be seen to keeping aggression away from important relationships. For example, a person who feels attacked by a colleague may hug her effusively at the next encounter and hereby transform the initial anger into its opposite, an unconscious mental transformation also called reaction formation. Examples for intermediate/neurotic defenses are turning against the self, pseudo-altruism or reaction formation. They can be helpful when applied with flexibility but are moderately related to the internal experience of psychological distress (22). 
Maladaptive defenses, on the other end of the spectrum, are mechanisms to exclude potentially threatening emotional negative affects from the self by, for example, projecting them on other people or by dissociating from them. Examples are projection, splitting, and projective identification. In contrast to more adaptive defenses, that operate on an intrapsychic level, maladaptive defenses are employed mainly interpersonally, hence using others to (unconsciously) regulate one's own emotional distress. The dominant use of these defense mechanisms is strongly related to relationship problems, psychiatric disorders, and personality pathology (23-28).

\section{Narcissism and Defenses}

From an etiologic point of view, defense mechanisms in narcissism are understood as a developmental consequence from early experiences of rejection and devaluation by primary caregivers $(29,30)$. In this context, it is argued that the grandiose manifestation of narcissism result from an unconscious compensatory process to defend oneself against severe anxieties, shame, and threats to the self-esteem $(18,20,21)$. By coining the term "character defense", Kernberg (17) argues that the core of the narcissistic pathology can be seen in a defensive operation to sustain the ego by splitting based, projective and realityexceeding defensive operations such as grandiose fantasies, omnipotence, devaluation and idealization of the self and others, denial and externalization. To date, there are only few empirical studies that have investigated mechanisms that are specifically related to narcissism: Perry and Perry (31) found devaluation, omnipotence, idealization, and mood-incongruent denial as specific narcissistic defensive operations. Hilsenroth et al. (32) found idealization, and Raskin and Novacek (33) identified grandiose fantasies as defense mechanisms as specifically related to narcissism. The unconscious use of these mechanisms has the goal of preventing unpleasant realities from the consciousness to sustain the world of omnipotence, importance, and grandiose fantasy (17).

\section{Grandiose and Vulnerable Narcissism}

The concept of narcissism has widely been formed by the grandiose phenotype which, to date, still is the underlying concept in the international classification systems of psychiatric diseases $(34,35)$. Due to criterion problems and related inconsistencies (36), the mere focus on the grandiose side of narcissism was criticized and subsequently investigated and revised (9). In spite of former differentiations between normal and pathological narcissism, there is a growing consensus toward a dimensional conceptualization with normal and pathological narcissisms as two poles of the spectrum (14). Furthermore, research on underlying factors of narcissism has emerged: Numerous studies found different factor structures in narcissism: Besides five (37), and three (16, 38, 39) factor solutions, prevailing evidence supports the assumption of two distinct factors in narcissism, namely grandiose (GN) and vulnerable (VN) narcissism (9, 16, 40-45).

While psychoanalytic theory suggests $\mathrm{VN}$ to be the underlying insecurity of GN, empirical research suggests that both are distinct factors of narcissism with fluctuating expressions (41, 46-48). Intriguingly, the two facets of narcissism show very distinct clinical appearances. GN is linked to higher selfesteem, self-construal, and extraversion $(2,41,49)$ and associated with higher sensibility to achievement setbacks (50). It is furthermore related to a hedonistic orientation and risktaking behavior, impulsivity, and little consideration for future consequences (48) and also related to less treatment utilization and more drop-out (4). VN on the contrary is related to lower self-esteem, interdependent self-construal, attachment anxiety (49), introversion (41), sensitivity to shaming interpersonal experiences (50), a fatalistic and negative life perspective (48), and a hostile attribution bias (112).

While GN is generally associated with better psycho-social functioning, life satisfaction, and psychological health $(1,2), \mathrm{VN}$ is related to neuroticism (51), higher psychological distress and depressive symptoms $(1,52)$, and less life satisfaction (2). It is also associated with difficulties in accessing adaptive emotion regulation strategies (53) and overall considered to be more dysfunctional. While $\mathrm{GN}$ is related to narcissistic personality disorder, $\mathrm{VN}$ is related to borderline personality disorder with severe impairments in psychological functioning (54).

Due to the clinical relevance and the particular relationship between narcissistic features and clinical challenges, treatment difficulties and lack of therapeutic response $(3,6,7)$, the concept of narcissism has gained increasing attention in clinical conceptualizations and empirical research. The role of emotion regulation strategies related to narcissism has thereby shown to be of central clinical relevance. Recent studies have examined the relationship between dimensions of pathological narcissism and depressive symptoms, finding a consistent association between pathological narcissism and depressive symptoms in a longitudinal design (55), discussing emotional processing abilities as possible mediator (in VN) (56), and the role of dysfunctional attitudes like perfectionism in explaining the link between VN and depression (57).

Another avenue of research is the finding of a robust and projective defensive structure as a central factor in complications, refusals of change, drop-outs or stagnating treatment courses $(3,7,8,20,58,59)$. A study with narcissistic psychiatric outpatients showed an association between high levels of narcissism and greater interpersonal impairment by engaging in domineering, vindictive, and intrusive behaviors and a failure to complete treatment $(5,60)$. Mielimaka et al. (61) later found that the defensive style mediated the relationship between narcissism and interpersonal problems: Albeit narcissism was not directly related to interpersonal problems, they found an indirect effect when mediated by neurotic defense mechanisms. Ultimately, the differentiation between $\mathrm{GN}$ and $\mathrm{VN}$ has shown to be of informative value: Studies on the relationship between pathological narcissism (GN and VN), defensive functioning, and coping abilities have shown that GN and $\mathrm{VN}$ are associated with diverging coping strategies (62). VN, but not GN, is associated with hostile attribution bias, which could be interpreted as projective processes (63), and VN was strongly associated with narcissistic rage, hostility and aggressive behavior (64). The diverging relationships of $\mathrm{GN}$ and $\mathrm{VN}$ with emotion regulation strategies hence seem to be of high clinical relevance and deserve further investigation. 


\section{Aims of the Current Study}

Our aim was to further elucidate this issue by considering the role that defense mechanisms play in the paradoxical relationship between narcissism and psychological distress. Firstly, we aimed to explore specific defense mechanisms that are used in GN and in VN, respectively. Secondly, we aimed to explore the differential associations between GN and VN and psychological distress. Thirdly, we assumed that taking defense mechanisms into consideration might shed light on the relationship between narcissism and distress and may thus help to resolve the contradictions between grandiose narcissism and its ambiguous association with psychological distress. For this we conducted a cross-sectional study in which we assessed GN, VN, defense mechanisms and indicators of psychological distress in a nonclinical sample.

\section{MATERIALS AND METHODS}

Our study has been preregistered at Open Science Forum (OSF). A detailed description of the research project and the full study plan can be accessed via the following link https://osf.io/9tuqd/.

\section{Participants}

A non-clinical sample of $N=254$ (192 females, 59 males, and three with no specified gender) individuals was recruited via university and general mailing lists and assessed by an online survey as part of a larger study on personality, defenses and attachment (not relevant for the current thrust). Approval of the ethics committee of the Psychologische Hochschule Berlin was obtained. Inclusion criteria was a minimum age of 18 years and sufficient German language skills. A descriptive analysis of the sample is given in Table $\mathbf{1}$.

\section{Measures}

\section{Narcissism}

For the assessment of grandiose and vulnerable narcissism, we used the German version of the Pathological Narcissism Inventory [PNI, (65); English original version: (44)]. The German $\mathrm{PNI}$ is a multidimensional measure for grandiose and vulnerable features of pathological narcissism and contains 54 items. It includes a translation of the 52 items of the original English PNI plus two additional items for the exploitative subscale, constructed and validated by the authors of the German version. The PNI consists of the following seven subscales: exploitativeness (EXP, seven items, e.g., item 15: "I find it easy to manipulate people"), grandiose fantasy (GF, seven items, e.g., item 42: "I often fantasize about performing heroic deeds"), self-sacrificing self-enhancement (SSSE, six items, e.g., item 22: "I feel important when others rely on me"), entitlement rage (ER, eight items, e.g., item 29: "I get angry when criticized"), devaluing (DEV, seven items, e.g., item 17: "Sometimes I avoid people because I'm concerned that they'll disappoint me"), contingent self-esteem (CSE, 12 items, e.g., item 36: "It's hard to feel good about myself unless I know other people like me"), and hiding the self (HS, seven items, e.g., item 9: "I often hide my needs for fear that others will see me as needy and dependent"). Items are scored on a 6-point Likert scale
TABLE 1 | Descriptive statistics

\begin{tabular}{|c|c|c|c|c|}
\hline & Mean & SD & Min & Max \\
\hline Age & 33.56 & 15.03 & 18 & 73 \\
\hline Psychological distress & 1.73 & 0.63 & 1.00 & 4.28 \\
\hline Grandiose narcissism & 3.19 & 0.75 & 1.40 & 5.15 \\
\hline Vulnerable narcissism & 3.04 & 0.79 & 1.00 & 5.56 \\
\hline \multicolumn{5}{|c|}{ Adaptive defense mechanisms } \\
\hline Suppression & 4.21 & 1.75 & 1 & 9 \\
\hline Anticipation & 5.36 & 1.69 & 1 & 9 \\
\hline Humor & 5.52 & 1.76 & 1 & 9 \\
\hline Sublimation* & 3.70 & 2.23 & 1 & 9 \\
\hline Rationalization* & 6.23 & 1.58 & 2 & 9 \\
\hline Denial $^{*}$ & 2.46 & 1.73 & 1 & 9 \\
\hline Dissociation & 3.10 & 1.58 & 1 & 7.5 \\
\hline \multicolumn{5}{|c|}{ Intermediate/neurotic defense mechanisms } \\
\hline Pseudo-altruism & 4.96 & 1.44 & 1 & 8.5 \\
\hline Undoing & 4.08 & 1.75 & 1 & 9 \\
\hline Reaction formation* & 4.45 & 2.21 & 1 & 9 \\
\hline Acting out & 3.53 & 1.75 & 1 & 8.5 \\
\hline \multicolumn{5}{|c|}{ Maladaptive defense mechanisms } \\
\hline Splitting & 2.68 & 1.64 & 1 & 7.5 \\
\hline Autistic fantasy & 3.11 & 2.06 & 1 & 9 \\
\hline Projection & 2.17 & 1.42 & 1 & 8 \\
\hline Passive aggression & 2.50 & 1.52 & 1 & 9 \\
\hline Idealization & 3.10 & 1.58 & 1 & 7.5 \\
\hline Somatization & 3.35 & 1.84 & 1 & 9 \\
\hline Isolation & 3.25 & 1.94 & 1 & 9 \\
\hline Displacement & 3.48 & 1.84 & 1 & 9 \\
\hline Devaluation & 3.28 & 1.54 & 1 & 8.5 \\
\hline
\end{tabular}

For all scales, the mean values over all items are displayed. For psychological distress the rating scales ranged from 1 to 5; for grandiose and vulnerable narcissism the ratings scales ranged from 1 to 6 ; for the defense mechanisms the rating scales ranged from 1 to 9.

${ }^{*}$ For this defense mechanism only one item was used.

ranging from 0 (not at all like me) to 5 (very much like me). The PNI shows overall good psychometric properties with alpha coefficients ranging between $\alpha=0.82$ and $\alpha=0.92$. Re-test reliability for the total score was at $\alpha=0.86$ and CFA and ESEM confirmed the 7-factor lower order factor structure (65). Conclusions for higher order factor structures still remain open, however, empirical evidence suggests a two-factor solution for grandiose narcissism consisting of factors EXP, GF, and SSSE, and vulnerable narcissism consisting of factors ER, DEV, HS and CSE (44, 65-68). We based our analyses on this two-factor solution.

\section{Defense Mechanisms}

The Defense Style Questionnaire [DSQ 40, (69)] is the 40 item German version of the English DSQ 40 (70). In the DSQ, 20 defense mechanisms, represented by two items each, are assessed on a 9-point Likert scale ranging from 1 (strongly disagree) to 9 (strongly agree). The items can be classified into three categories, each forming an individual scale: adaptive, intermediate (neurotic), and maladaptive defense mechanisms. The respective 
$\epsilon_{11}$

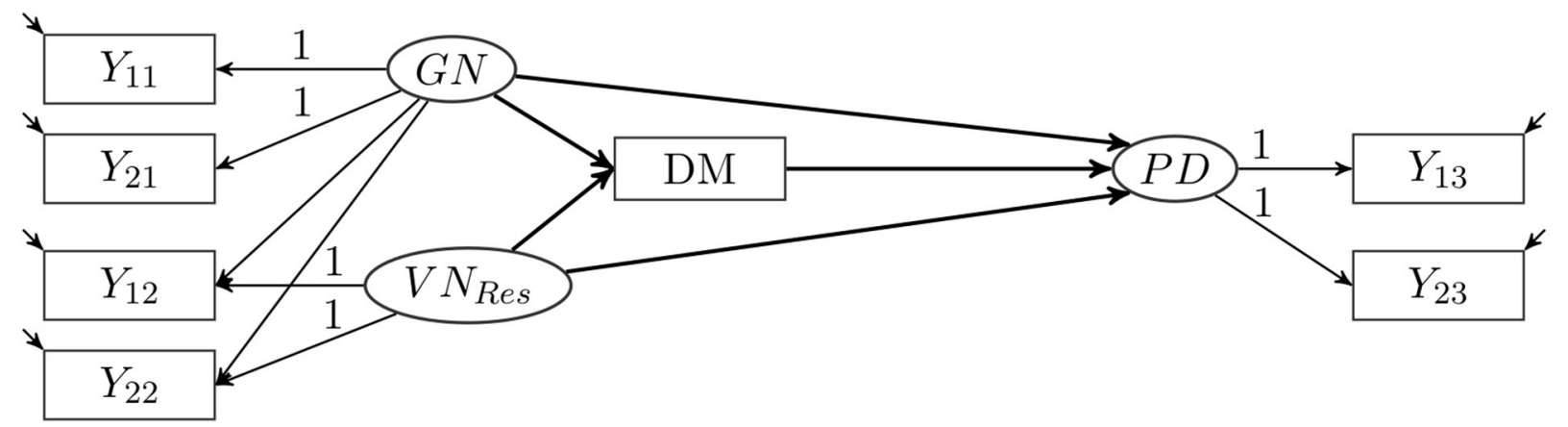

FIGURE 1 | Structural equation model of grandiose and vulnerable narcissism, defense mechanisms, and psychological distress.

items are marked as such in the results. Factor analysis of the German version confirmed the original factor structure but assigned individual defense mechanisms to the three factors in a different pattern: adaptive defenses (sublimation, humor, anticipation, suppression, rationalization, dissociation, and denial), intermediate/neurotic defenses (pseudo-altruism, undoing, reaction formation, and acting out), and maladaptive defenses (splitting, autistic fantasies, projection, passive aggression, idealization, somatization, isolation, displacement, and devaluation) (69). Other studies on the DSQ 40 vary in the assignment of the individual defense mechanisms to their levels of adaptiveness. For our study we based the assignment on the factor analysis of Schauenburg et al. (69), although some clincal doubts might remain. However, since we did not use the scale means for our analysis, the assignment is irrelevant for the interpretation of our results.

\section{Psychological Distress}

For the assessment of psychological distress, we used the German version of the Brief Symptom Inventory [BSI-18; German version: Mini-SCL, (71)]. The BSI-18 is a reliable and short instrument for the assessment of clinical distress to assess subjective mental impairment on the scales depression $(\alpha=$ $0.87)$, anxiety ( $\alpha=0.84)$, and somatization $(\alpha=0.82)$ (72). Items are rated on a 5-point Likert scales ranging from 0 (not at all) to 4 (extremely). For this study, we used the Global Severity Index (GSI, $\alpha=0.93$ ), an overall score for psychological distress that can be calculated from the three subscales. Both, first and second order factor structures were supported by CFA (72).

\section{Statistical Analysis}

For an a priori calculation of the sample size, comparable studies served as orientiation [e.g., $(73,74)$ ] for the calculation of the correlations. These studies show an average effect sizes of $r=$ 0.3 . A power analysis for the calculation of the sample size was conducted with the program $G^{*}$ Power 3.1 (75). With an alpha error probability of 0.05 , an estimated power of 0.95 and the estimated effect size of $r=0.3$, a sample size of 134 participants resulted from the analysis. As structural equation models require a minimum of $N=200$ (76) we used this as the study's benchmark.

Structural equation modeling was used to address the questions in this study. These models combine the different facets of narcissism (assessed by PNI), defense mechanisms (assessed by DSQ 40), and psychological distress (assessed by BSI-18) into one model. The model is displayed in Figure 1.

To represent the different correlations of GN and VN with the other variables, we used a bifactor S-1 model $(77,78)$. This S-1 model allows a clear separation of grandiose and vulnerable aspects of narcissism. Since GN is the core of the current definition of pathological narcissism, it was chosen as the reference factor for the model. Based on prior research and modeling suggestions $(44,65,68)$ two parcels $\left(Y_{11}\right.$ and $\left.Y_{21}\right)$ were calculated from the items of the PNI scales for EXP, GF, and SSSE. These two parcels load on the GN factor, which represents the degree of grandiose narcissism. Two other parcels $\left(Y_{12}\right.$ and $Y_{22}$ ) were calculated from the remaining items of the PNI, which form the CSE, DEV, ER, and HS scales. These two parcels also load on the GN factor. These two parcels additionally load on a second factor $\mathrm{VN}_{\text {Res }}$ that is uncorrelated with the GN factor. This second factor is a residual factor, and it describes that portion in the variance of vulnerable narcissism that cannot be explained by GN. This residual factor has the mean value 0 and a person with a value of 0 in this factor would have exactly the value in the VN that would be expected on the basis of the GN. Thus, a person with a positive value on this residual factor would have a higher VN than one would have expected based on their GN. Through this approach, the GN factor represents the grandiose elements of narcissism, encompassing the elements contained in both GN and VN. The residual factor of VN contains only those elements that have nothing in common with GN. By separating the reference and the residual factor, we can better examine the influence on other variables the specific vulnerable facet of narcissism has independently of grandiose narcissism.

For each defense mechanism, an individual model was calculated, leading to a total of 20 models. Each defense mechanism also formed a mediator between the two narcissism factors and psychological distress. Two parcels $\left(Y_{13}\right.$ and $\left.Y_{23}\right)$ were calculated from the items of the BSI-18 and loaded on the 


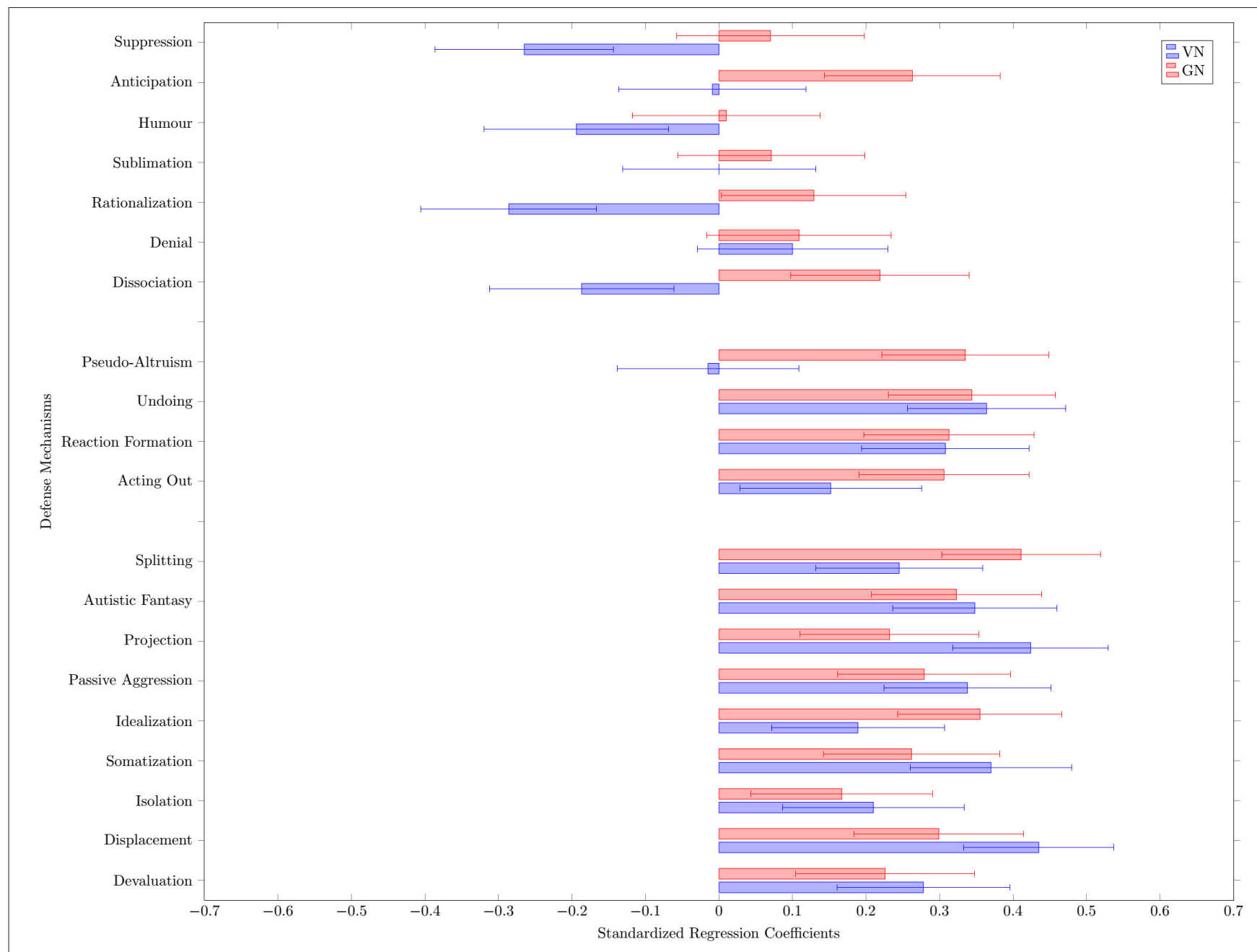

FIGURE 2 | Influence of grandiose and vulnerable narcissism on defense mechanisms: standardized regression coefficients and their confidence intervals.

psychological distress factor. We used this model to examine the strength of the relationship between the narcissism factors and the respective defense mechanism, the strength of the influence on psychological distress, and to what extent this influence is mediated by the defense mechanism.

The defense mechanisms were each comprised of two items and the mean of these two items was used as a manifest variable in the model. For the defense mechanisms of sublimation, rationalization, reaction formation, and denial, the correlations of the two items were not significant. In each of these models, only the item that represented the defense mechanism best in terms of content was used.

The model was evaluated with Mplus 8 using a maximum likelihood estimator. The goodness-of-fit of all models was examined with the $\chi^{2}$-Test, the CFI, and the RMSEA. A good model fit is indicated by a value of $\chi^{2}<2 * d f$, a CFI $>0.97$, and a RMSEA $<0.05$; an acceptable model fit is indicated by a value if $\chi^{2}<3^{*} d f$, a CFI $>0.95$, and a RMSEA $<0.08(79)$.

\section{RESULTS}

The model fit of all models are displayed in the Appendix. In 14 models the model fit was good and in five models the model fit was acceptable (in these models, the RMSEA was above 0.05 but below 0.08 ; the other model fit indices indicated a good model fit). Only in the model with projection, the model fit was too low $\left(\mathrm{RMSEA}=0.092\right.$ and $\chi^{2}=34.48$ with $\left.\mathrm{df}=11\right)$. The results of this model should be interpreted with caution. The results of this study use the standardized regression coefficients $b$ of the structural equation model, the size of which can be interpreted as correlations.

Descriptive statistics are displayed in Table 1. As expected in a non-clinical sample, participants used more adaptive defense mechanisms such as rationalization, humor, and anticipation than other defense mechanisms. Suppression and intermediate/neurotic defense mechanisms were employed occasionally, and maladaptive defense mechanisms were 
TABLE 2 | Direct and indirect effects of narcissism on psychological distress mediated by defense mechanisms.

\begin{tabular}{|c|c|c|c|c|c|c|c|}
\hline \multirow[t]{2}{*}{ Model } & \multicolumn{2}{|c|}{ Effects on DM } & \multicolumn{5}{|c|}{ Effects on psychological distress } \\
\hline & GN & $\mathbf{V N}_{\mathrm{Res}}$ & DM & GN direct & GN indirect & $\mathrm{VN}_{\text {Res }}$ direct & $\mathrm{VN}_{\text {Res }}$ indirect \\
\hline \multicolumn{8}{|l|}{ Adaptive } \\
\hline Suppression & 0.070 & $-0.265^{\star}$ & -0.028 & 0.110 & -0.002 & $0.492^{*}$ & 0.007 \\
\hline Anticipation & $0.263^{\star}$ & -0.009 & -0.012 & 0.112 & -0.003 & $0.499^{\star}$ & 0.000 \\
\hline Humor & 0.010 & $-0.194^{*}$ & 0.078 & 0.105 & 0.001 & $0.514^{*}$ & -0.015 \\
\hline Sublimation & 0.071 & 0.000 & $0.126^{\star}$ & 0.101 & 0.009 & $0.501^{*}$ & 0.000 \\
\hline Rationalization & $0.129^{\star}$ & $-0.286^{\star}$ & -0.046 & 0.114 & -0.006 & $0.486^{\star}$ & 0.013 \\
\hline Denial & 0.109 & 0.100 & 0.006 & 0.107 & 0.001 & $0.499^{\star}$ & 0.001 \\
\hline Dissociation & $0.219^{*}$ & $-0.187^{\star}$ & 0.034 & 0.101 & 0.007 & $0.505^{\star}$ & -0.006 \\
\hline \multicolumn{8}{|c|}{ Intermediate/neurotic } \\
\hline Pseudo-altruism & $0.335^{\star}$ & -0.015 & -0.018 & 0.113 & -0.006 & $0.499^{\star}$ & 0.000 \\
\hline Undoing & $0.344^{\star}$ & $0.364^{*}$ & 0.126 & 0.062 & 0.043 & $0.453^{*}$ & 0.046 \\
\hline Reaction formation & $0.313^{\star}$ & $0.308^{*}$ & $0.187^{\star}$ & 0.047 & $0.058^{\star}$ & $0.441^{\star}$ & $0.058^{\star}$ \\
\hline Acting out & $0.306^{\star}$ & $0.152^{*}$ & $0.236^{\star}$ & 0.032 & $0.072^{\star}$ & $0.464^{*}$ & $0.036^{\star}$ \\
\hline \multicolumn{8}{|l|}{ Maladaptive } \\
\hline Splitting & $0.411^{\star}$ & $0.245^{\star}$ & $0.240^{\star}$ & 0.011 & $0.099^{\star}$ & $0.443^{\star}$ & $0.059^{\star}$ \\
\hline Autistic fantasy & $0.323^{\star}$ & $0.348^{\star}$ & $0.259^{\star}$ & 0.025 & $0.084^{\star}$ & $0.410^{\star}$ & $0.090^{\star}$ \\
\hline Projection & $0.232^{*}$ & $0.424^{*}$ & $0.235^{\star}$ & 0.056 & $0.054^{*}$ & $0.400^{\star}$ & $0.100^{\star}$ \\
\hline Passive aggression & $0.279^{*}$ & $0.338^{*}$ & $0.211^{*}$ & 0.051 & $0.059^{*}$ & $0.429^{\star}$ & $0.071^{*}$ \\
\hline Idealization & $0.355^{\star}$ & $0.189^{\star}$ & $0.157^{\star}$ & 0.050 & $0.056^{\star}$ & $0.471^{*}$ & $0.030^{\star}$ \\
\hline Somatization & $0.262^{*}$ & $0.370^{*}$ & $0.380^{\star}$ & 0.009 & $0.100^{\star}$ & $0.360^{\star}$ & $0.141^{\star}$ \\
\hline Isolation & $0.167^{\star}$ & $0.210^{*}$ & $0.247^{\star}$ & 0.069 & $0.041^{*}$ & $0.450^{\star}$ & $0.052^{\star}$ \\
\hline Displacement & $0.299^{\star}$ & $0.435^{\star}$ & $0.258^{\star}$ & 0.030 & $0.077^{\star}$ & $0.388^{\star}$ & $0.112^{\star}$ \\
\hline Devaluation & $0.226^{\star}$ & $0.278^{\star}$ & $0.166^{\star}$ & 0.071 & $0.037^{\star}$ & $0.455^{\star}$ & $0.046^{\star}$ \\
\hline
\end{tabular}

The 20 models differ in the defense mechanism.

$D M=$ defense mechanism; $G N=$ grandiose narcissism factor; $V N_{\text {Res }}=$ vulnerable narcissism residual factor.

*Significant effect.

reported least frequently. In terms of psychological distress, we found rather low levels $(M=1.73, S D=0.63)$ which is also expected in a non-clinical sample. Similar scores for GN $(M=$ $3.19, S D=0.75)$ and $\mathrm{VN}(M=3.04, S D=0.79)$ were found. The associations between the specific defense mechanisms and psychological distress are depicted in Table 2.

\section{Associations Between Grandiose and Vulnerable Narcissism and Specific Defense Mechanisms}

The associations are displayed in Figure 2 and can also be found in Table 2. GN showed significant positive associations with adaptive defense mechanisms anticipation $(b=0.26)$, rationalization $(b=0.13)$, and dissociation $(b=0.22)$; intermediate/neurotic defense mechanisms pseudo altruism $(b$ $=0.36)$, undoing $(b=0.34)$, reaction formation $(b=0.31)$, and acting out $(b=0.31)$; and maladaptive defenses splitting $(b=0.41)$, idealization $(b=0.36)$, autistic fantasies $(b=$ $0.32)$, displacement $(b=0.30)$, passive aggression $(b=0.28)$, somatization $(b=0.26)$, devaluation $(b=0.23)$, projection $(b=$ $0.23)$, and isolation $(b=0.17)$.

VN showed significant negative associations with the adaptive defense mechanisms rationalization $(b=-0.29)$, suppression $(b=-0.27)$, humor $(b=-0.19)$ and dissociation $(b=$ $-0.19)$. VN showed significant positive associations with the intermediate/neurotic defenses undoing $(b=0.36)$, reaction formation $(b=0.31)$, and acting out $(b=0.15)$ and with the maladaptive defenses displacement $(b=0.44)$, projection $(b=$ $0.42)$, somatization $(b=0.37)$, autistic fantasies $(b=0.35)$, passive aggression $(b=0.34)$, devaluation $(b=0.28)$, splitting ( $b=0.25)$, isolation $(b=0.21)$, idealization $(b=0.19)$.

Overall, in this non-clinical sample, GN seemed to be associated with most adaptive defense mechanisms and especially with all maladaptive and intermediate/neurotic defense mechanisms, while VN was negatively associated with adaptive mechanisms and strongly positively associated with maladaptive and neurotic defense mechanisms.

\section{Associations Between Grandiose and Vulnerable Narcissism and Psychological Distress}

In order to estimate the association of narcissism and psychological distress regardless of a defense mechanism, a reduced model was estimated. This model is like the model in Figure 1, but without the defense mechanism. This reduced 
model had a very good model fit $\left(\chi^{2}=9.89, d f=8, p=\right.$ $0.27, \mathrm{RMSEA}=0.031, \mathrm{CFI}=0.99)$. In the reduced model, GN had no significant association with psychological distress $[b=$ $0.107, p=0.108,95 \%-\mathrm{KI}:(-0.024 ; 0.238)]$. The residual factor of $\mathrm{VN}$ had a significant, positive association with psychological distress $[b=0.500, p<0.001,95 \%-\mathrm{KI}$ : $(0.396 ; 0.603)]$. This is a large association. Participants who reported higher vulnerable narcissism than expected based on their grandiose narcissism reported more psychological distress.

\section{Mediator Analysis of Defense Mechanisms Between Narcissism and Psychological Distress}

The results for the mediation analysis can be found in the last four columns of Table 2. Both GN and VN had indirect effects on psychological distress. The indirect effects were mediated by the corresponding defense mechanism of the model. No significant direct effect of GN on psychological distress was found. In contrast, strong direct effects of $\mathrm{VN}$ on psychological distress were found. GN showed significant indirect effects on psychological distress when mediated by specific defense mechanisms. More specifically, this mediation was found in models with reaction formation and acting out (from the intermediate/neurotic defense category) and in all models with maladaptive defense mechanisms. For VN, significant indirect effects on psychological distress mediated by the defense mechanisms could be found for the same models. This means, that individuals with higher levels of vulnerable and grandiose narcissism reported more maladaptive defense mechanisms and therefore more psychological distress.

\section{DISCUSSION}

The aim of the current study was to investigate the nature and role of defense mechanisms in grandiose and vulnerable facets of narcissism in a non-clinical sample. First, we aimed to explore defense mechanisms that are typical for GN and VN, respectively. Second, we aimed to replicate past findings showing that GN and $\mathrm{VN}$ are differentially related to psychological distress, assuming that GN would not be related to psychological distress and VN would be strongly related to psychological distress. Third, we assumed that specific defense mechanisms would shed light on the former differential narcissism-distress interplay and therefore explored whether and which defense mechanisms mediated the association between psychological distress and $\mathrm{VN}$ and GN, respectively.

To address our research questions we analyzed data of $N$ $=254$ healthy subjects with structural equation modeling and employed a bifactor S-1 model $(77,78)$. The latter allowed us to separate statistically grandiose and vulnerable aspects of narcissism. Since GN is the core of the current definition of pathological narcissism, it was chosen as the reference factor for the model.

Overall, specific defense mechanisms for both types of narcissism could be found. First, we found differences between GN and VN and the adaptiveness of their defensive structure:
Both GN and VN were related to almost all intermediate/neurotic and maladaptive defense mechanisms. However, only GN was significantly positively related to the use of adaptive defense mechanisms. Since the use of adaptive defense mechanisms is related to mental health, this finding might be one of the explanations why GN is not associated with psychological distress while VN is. Second, we found that those defense mechanisms that were exclusively found in GN, were not only non-related, but significantly negatively related to VN. These mechanisms are pseudo-altruism, rationalization, anticipation, and dissociation. Only these mechanisms did not mediate the relationship between GN and psychological distress. This leads to the assumption that the use of these particular mechanisms in GN might be the strategical "advantage" of GN compared to $\mathrm{VN}$ when regulating psychological distress. Third, we found overall qualitative differences with regard to the defense mechanisms for GN and VN: The defense mechanisms showing the strongest association with grandiose narcissism are splitting-based (e.g., splitting, idealization, and devaluation) and socially desirable (e.g., pseudo altruism, anticipation, and rationalization). $\mathrm{VN}$ on the contrary was most strongly associated with defense mechanisms that can be summarized as related to dissociating the affect from the self (e.g., somatization, projection, autistic fantasies, and displacement) and self-directed defense mechanisms (e.g., reaction formation, undoing, and passive aggression). Overall, GN appeared to be related to the more effective and more socially desirable defensive styles than VN.

The current findings are in line with existing research on defense mechanisms in narcissism: Zeigler-Hill and Besser (80) found that GN was positively related with the use of adaptive humor (self-enhancing and affiliative), whereas VN was negatively associated with adaptive humor and positively with maladaptive humor (self-defeating and aggressive). Richardson and Boag (81) found defense mechanisms acting out, dissociation, and splitting for grandiose psychopathological narcissism and further showed that immature defensive strategies mediate the relationship between Machiavellianism and distress. Fernie et al. (62) found denial to be especially prominent in VN. Mielimaka et al. (61) reported a strong relationship between immature and neurotic defenses based on the DSQ and pathological narcissism, albeit not differentiating between GN and VN. To our best knowledge, the only existing study on defense mechanisms, differentiating between GN and VN, has recently been published by Khodabakhsh Pirklany and Safaeian (82), finding high expressions of GN and VN related to intermediate/neurotic and maladaptive defenses, and this being significantly higher than for individuals with low expressions in pathological narcissism.

With regard to psychological distress, GN was not directly related to psychological distress, whereas $\mathrm{VN}$ was directly related to psychological distress. Since VN is a residual factor in our study, the result means that it is not the global measure of GN that is related to psychological distress, but only the VN that exceeds the measure of GN. Individuals who are less vulnerably narcissistic than would be expected based on their GN report lower psychological distress. These findings corroborate existing research on the role of coping flexibility and emotion regulation 
in GN and VN. Ng et al. (83) identified more flexible coping with stress in GN as a crucial mediating factor that makes them appear psychologically healthier than VN. Di Pierro et al. (53) emphasized these differences in accessing adaptive emotion regulation strategies by demonstrating that VN was associated with emotion regulation difficulties, and in understanding, accepting, and being clear about emotional states, whereas GN was not. Also, Zhang et al. (84) showed that VN was positively correlated with emotion dysregulation. Fernie et al. (62) found that unlike GN, VN was significantly associated with the use of denial as coping with stress response when controlling for anxiety and social desirability and behavioral disengagement. HansenBrown and Freis (63) found that a hostile attribution bias is exclusively found in VN, not in GN.

Intriguingly, the mediator analysis of defense mechanisms on the relationship between GN and $\mathrm{VN}$ and psychological distress seems to turn the tables for GN: Even though not directly related to psychological distress, GN showed significant positive associations with psychological distress when mediated by maladaptive defense mechanisms. These findings strongly highlight the central role of defense mechanisms in understanding the concept and pathological core of grandiose narcissism. The underlying defensive structure of the grandiose facet seems to expose its vulnerability and furthermore explains the relationship between GN and VN. A study of Mielimaka et al. (61) found similar results for narcissism, which can be considered comparable since the used measures base their operationalization of narcissism on its grandiose facet: they found that pathological narcissism itself was not directly related with interpersonal problems but indirectly related when mediated by neurotic defense mechanisms. Following this thought, an interesting finding of Jauk and Kaufman (40) on the relationship between GN and VN revealed that solely the severity of grandiosity explains the difference between the two facets and that GN and $\mathrm{VN}$ may be dissociable at lower levels of grandiosity but merge into an antagonistic core with signs of psychological maladjustment at higher levels.

\section{The Role of Defense Mechanisms in Diagnosing Personality Impairment}

Our findings entail numerous clinical implications which are of particular relevance in the light of the current revisions of the DSM-5 classification and diagnostic approach toward personality disorders [for a review: (85)]. With the inclusion of the Level of Personality Functioning Scale [LPFS; (86)] in the appendix of DSM-5 Alternative Model for Personality Disorders (AMPD), a dimensional approach for diagnosing personality disorders on the dimensions identity, self-direction, empathy, and intimacy is introduced. The model suggests to abandon the prevailing categories and focus on diagnosing underlying impairments in personality functioning. To date, numerous studies have supported this dimensional model to be more accurate and clinically more useful than the categorical approach $(87,88)$. Even though defense mechanisms are not part of the LPFS, preliminary studies indicate that defenses may add to the assessment of severity of personality impairment (89). In a subsequent clinical analysis of outliers, whose markers for clinical severity were significantly underestimated by the rating of the LPFS, Kampe (90) found that these were mainly personalities with high expressions of GN. In a comparison with a measure that includes defense mechanisms (91) personality impairments were accurately detected with a measure assessing defense mechanisms. These preliminary findings in clinical case analyses support our findings on maladaptive defense mechanisms in GN as a core element of its potential psychopathology. It emphasizes that considering defense mechanisms into revisions of the model for diagnosing personality disorders would be helpful. Defense mechanisms had already been included in DSM-IV-TR but been waived again in further revisions (12).

\section{Theoretical Implications and Clinical Relevance}

The phenomenon of narcissism is of particular interest to the clinical field. Due to numerous difficulties in diagnostic approaches of pathlogical narcissism, the improvement in psychotherapeutic treatment is frequently overestimated. Not rarely treatment courses of narcissistic patients end with unpleasant surprises and sudden dropouts, fights, or an inability to end the treatment and separate from the therapist (8). Overall, our findings extend recent studies showing the interpersonal burden pathological narcissism places on relationships, both in daily life (92) and in clinical settings (93). These challenging interpersonal patterns are visible in treatment complications like drop-outs (4), the need for tact and sensitivity and therapist's adaptiveness when dealing with problematic relationship patterns (94), underlying shame (95) and the need for the therapist to turn to both fragile vulnerable aspects and provocative grandiose aspects of pathological narcissism (96).

Often there is little change in the personality and a sense of guardedness in the patient. This struggle has led Kernberg to write an article on "the almost untreatable narcissistic patient" (7), explaining these difficulties and emphasizing the role of defense mechanisms: Due to the rigid defensive structure, these patients don't admit their mental difficulties and make a big effort to constantly impress the therapist with good behaviors, charming attitudes, and superficial improvement. These psychoanalytic conclusions have already been revealed in empirical studies: Dickinson and Pincus (97) found that GN and VN reported domineering and vindictive interpersonal problems but GN denied interpersonal distress whereas VN reported high distress. Kaufman et al. (42) demonstrated that GN was not correlated with psychopathology and positively associated with life satisfaction but was also associated with multiple indicators of inauthenticity. Arikan (59) indicated that narcissistic defenses strongly relate to a tendency to devaluate and stigmatize mental illness, whereas adaptive defenses do not. This might explain the guardedness in narcissism when it comes to admitting mental distress. Our conclusions on the central role of defense mechanisms in narcissism complement these findings and further contribute to possible explanations of clinical difficulties with important implications for therapeutic approaches. It strengthens the assumption of defense mechanisms being the heart of the narcissistic pathology, or as Kernberg termed it, narcissism itself 
being a "character defense" (17). Our findings show the twosidedness of the narcissistic defense structure: on the one hand, it prevents the experience of psychological distress, and on the other hand it depicts the core of the pathology. The inclusion of defensive operations in the understanding, diagnostic and treatment of (grandiose) narcissism is hence important for an accurate and successful treatment (7). One treatment for (narcissistic) personality disorders especially developed based on this assumption is Transference Focused Psychotherapy (TFP) by the group of Kernberg $(6,98-100)$. Based on working with countertransference, this treatment focuses on the extraction, clarification, and interpretation of projective defensive operations, aiming to help the patients understand their mental representations and personality difficulties. Studies have supported the idea that besides symptom reduction, TFP successfully facilitates change from disorganized attachment representations to organized ones and leads to a notable improvement in mentalization abilities (99-106).

\section{On the Relationship Between Grandiose and Vulnerable Narcissism}

Eventually, this study adds to the discussion of the global operationalization of the concept of narcissism with GN and $\mathrm{VN}$ as potentially underlying factors. In our non-clinical sample, we did not find GN and VN as distinct factors with our initial modeling attempts. Instead, we built $\mathrm{GN}$ as a reference factor and $\mathrm{VN}$ as a residual factor. This raises the question of the relationship between $\mathrm{GN}$ and $\mathrm{VN}$ and whether they are two sides of a medal or fluctuating, if not overlapping constructs. Understanding the grandiose side as a defensive shield to protect the self from the conscious experience of the vulnerable side, our findings offer another perspective on the relationship between GN and VN. This leads to the assumption that individuals with narcissistic features might as well oscillate between grandiosity and vulnerability, which is compatible with the implications of Jauk and Kaufman (40), Jauk et al. (41), Gore and Widiger (46), and Oltmanns and Widiger (47). Even though this would support psychoanalytic theory on the concept of narcissism, further empirical studies to explore this relationship are still needed.

\section{Limitations}

Even though our findings are in line with expectations derived from psychoanalytic theory and supported by prior research in related fields, a limitation to our study is that our findings only are based on a non-clinical sample that might not represent the pathological expressions of the constructs sufficiently. Particularly, the current sample demonstrated relatively low levels of psychological distress. This might be especially relevant for the associations between GN and psychological distress which could be expected to be more strongly and directly related in a clinical sample with higher levels at the pathological end of the spectrum than in this relatively healthy population. Future studies should replicate the results with clinical samples with expectedly higher distress and pathological narcissism levels. Furthermore, it is important to note that even though psychoanalytic theory draws causal conclusions, our study represents correlations, and no causal implications can be drawn due the cross-section design of the study.

\section{Perspectives}

Our study highlights the importance of the concept of defense mechanisms for the conceptualization, diagnosis, and treatment of narcissism. For further research and for possible further changes in the diagnostic dimensions of personality pathology, we recommend considering defense mechanisms as a relevant domain in narcissism and personality in general. Studies that strengthen this matter are still needed. As our findings only refer to a non-clinical sample, we furthermore recommend including the pathological spectrum of narcissism into further conclusions on the central role of defense mechanism. We believe that a deeper understanding of defense mechanisms in narcissism, personality pathology, and mental disorders in general would be useful for both research and clinical practice. Even though deriving from psychoanalytic theory, we emphasize the relevance of the concept of defense mechanisms for all traditions and approaches.

Overall, future research should not only assess the phenomenological manifestations of disorders in terms of symptoms but to also take underlying, shared mechanisms into account. As most psychological disorders are related to dysfunctional emotion regulation (107), the inclusion of more hidden, that is implicit and unconscious, ways of dealing with affects and stressors, may be a fruitful endeavor (108). This is also in line with research showing that most processes operate implicitly rather than explicitly $(109,110)$.

\section{DATA AVAILABILITY STATEMENT}

The raw data supporting the conclusions of this article will be made available by the authors, without undue reservation.

\section{ETHICS STATEMENT}

The studies involving human participants were reviewed and approved by Ethikkommission der Psychologischen Hochschule Berlin Prof. Dr. T. Storck Am Köllnischen Park 210179 Berlin. The patients/participants provided their written informed consent to participate in this study.

\section{AUTHOR CONTRIBUTIONS}

LK conceptualized the study and drafted the manuscript. LK and CR coordinated the assessment. JB conducted the analysis. SH-S contributed to planning and implementation of the study and writing. All authors critically revised the manuscript, contributed equally, and approved the final version to be published.

\section{FUNDING}

This research was facilitated by incentive funds of the Freie Universität Berlin.

\section{ACKNOWLEDGMENTS}

We would like to thank the Department of Psychiatry, Psychotherapy and Psychosomatic Medicine, Psychosoziales 
Zentrum Itzehoe, Itzehoe, Germany (Prof. Dr. A. Deister, head of department) for institutional support and the publication fee. We furthermore thank Helene

\section{REFERENCES}

1. Loeffler LA, Huebben AK, Radke S, Habel U, Derntl B. The association between vulnerable/grandiose narcissism and emotion regulation. Front Psychol. (2020) 11:2732. doi: 10.3389/fpsyg.2020519330

2. Rohmann E, Hanke S, Bierhoff H-W. Grandiose and vulnerable narcissism in relation to life satisfaction, self-esteem, and self-construal. J Individ Differ. (2019). doi: 10.1027/1614-0001/a000292

3. Campbell MA, Waller G, Pistrang N. The impact of narcissism on drop-out from cognitive-behavioral therapy for the eating disorders: a pilot study. J Nervous Mental Dis. (2009) 197:278-81. doi: 10.1097/NMD0b013e31819dc150

4. Ellison WD, Levy KN, Cain NM, Ansell EB, Pincus AL. The impact of pathological narcissism on psychotherapy utilization, initial symptom severity, and early-treatment symptom change: a naturalistic investigation. J Personal Assess. (2013) 95:291-300. doi: 10.1080/00223891.2012 742904

5. Ogrodniczuk JS, Piper WE, Joyce AS, Steinberg PI, Duggal S. Interpersonal problems associated with narcissism among psychiatric outpatients. $J$ Psychiatric Res. (2009) 43:837-42. doi: 10.1016/j.jpsychires.2008.12005

6. Diamond D, Yeomans FE, Stern B, Levy KN, Hörz S, Doering S, et al. Transference focused psychotherapy for patients with comorbid narcissistic and borderline personality disorder. Psychoanal Inquiry. (2013) 33:527-51. doi: 10.1080/07351690.2013815087

7. Kernberg OF. The almost untreatable narcissistic patient. J Am Psychoanal Assoc. (2007) 55:503-39. doi: 10.1177/00030651070550020701

8. Little R. Treatment considerations when working with pathological narcissism. Trans Anal J. (2006) 36:303-17. doi: 10.1177/03621537 0603600405

9. Cain NM, Pincus AL, Ansell EB. Narcissism at the crossroads: phenotypic description of pathological narcissism across clinical theory, social/personality psychology, and psychiatric diagnosis. Clin Psychol Rev. (2008) 28:638-56. doi: 10.1016/j.cpr.2007.09006

10. Levy KN. Subtypes, dimensions, levels, and mental states in narcissism and narcissistic personality disorder. J Clin Psychol. (2012) 68:886-97. doi: $10.1002 /$ jclp21893

11. Levy KN, Chauhan P, Clarkin JF, Wasserman RH, Reynoso JS. Narcissistic pathology: empirical approaches. Psychiatric Ann. (2009) 39:3. doi: 10.3928/00485713-20090401-03

12. American Psychiatric Association. Diagnostic and Statistical Manual of Mental Disorders. 5th ed. Washington, DC: APA (2013). doi: 10.1176/appi. books9780890425596

13. Pincus AL, Cain NM, Wright AG. Narcissistic grandiosity and narcissistic vulnerability in psychotherapy. Personal Disord Theory Res Treat. (2014) 5:439. doi: $10.1037 /$ per0000031

14. Roche MJ, Pincus AL, Lukowitsky MR, Ménard KS, Conroy DE. An integrative approach to the assessment of narcissism. J Personal Assess. (2013) 95:237-48. doi: 10.1080/00223891.2013770400

15. Miller JD, Gentile B, Wilson L, Campbell WK. Grandiose and vulnerable narcissism and the DSM-5 pathological personality trait model. J Personal Assess. (2013) 95:284-90. doi: 10.1080/00223891.2012 685907

16. Weiss B, Miller JD. Distinguishing between grandiose narcissism, vulnerable narcissism, narcissistic personality disorder. In: Hermann A, Brunell A, Foster J, editors. Handbook of Trait Narcissism. Cham: Springer (2018). doi: 10.1007/978-3-319-92171-6_1

17. Kernberg OF. Borderline Conditions and Pathological Narcissism. New York, NY: Aronson (1975).

18. Kernberg OF. Factors in the psychoanalytic treatment of narcissistic personalities. J Am Psychoanal Assoc. (1970) 18:51-85. doi: $10.1177 / 000306517001800103$
Harnisch, Ilva Heitmann, and Charlotte Weinmann for their help with data collection and conduction

19. Rice TR, Hoffman L. Defense mechanisms and implicit emotion regulation: a comparison of a psychodynamic construct with one from contemporary neuroscience. J Am Psychoanal Assoc. (2014) 62:693-708. doi: 10.1177/0003065114546746

20. Kernberg OF. Narcissistic defenses in the distortion of free association and their underlying anxieties. Psychoanal Quart. (2015) 84:625-42. doi: $10.1002 /$ psaq12022

21. Robins RW, Tracy JL, Shaver PR. Shamed into self-love: dynamics, roots, and functions of narcissism. Psychol Inquiry. (2001) 12:230-6. Available online at: http://www.jstor.org/stable/1449481

22. Vaillant GE, Bond M, Vaillant CO. An empirically validated hierarchy of defense mechanisms. Arch Gen Psychiatry. (1986) 43:786-94. doi: 10.1001/archpsyc.198601800080072010

23. Cramer P. Personality, personality disorders, and defense mechanisms. $J$ Personal. (1999) 63:4. doi: 10.1111/1467-649400064

24. Di Giuseppe M, Perry JC, Conversano C, Gelo OCG, Gennaro A. Defense mechanisms, gender, and adaptiveness in emerging personality disorders in adolescent outpatients. J Nerv Mental Dis. (2020) 208:933-41. doi: 10.1097/NMD0000000000001230

25. Lingiardi V, Lonati C, Delucchi F, Fossati A, Vanzulli L, Maffei C. Defense mechanisms and personality disorders. J Nerv Mental Dis. (1999) 187:224-8. doi: 10.1097/00005053-199904000-00005

26. Perry JC, Presniak MD, Olson TR. Defense mechanisms in schizotypal, borderline, antisocial, and narcissistic personality disorders. Psychiatry Interpersonal Biol Processes. (2013) 76:32-52. doi: 10.1521/psyc.2013. 76.132

27. Presniak MD, Olson TR, MacGregor MW. The role of defense mechanisms in borderline and antisocial personality. J Personal Assess. (2010) 92:137-45. doi: 10.1080/00223890903510373

28. Zanarini MC, Weingeroff JL, Frankenburg FR. Defense mechanisms associated with borderline personality disorder. J Personal Disord. (2009) 23:113-21. doi: 10.1521/pedi.2009.23.2113

29. Bennett CS. Attachment theory and research applied to the conceptualization and treatment of pathological narcissism. Clin Soc Work J. (2006) 34:45-60. doi: 10.1007/s10615-005-0001-9

30. Prunas A, Di Pierro R, Huemer J, Tagini A. Defense mechanisms, remembered parental caregiving and adult attachment style. Psychoanal Psychol. (2018) 36:64-72. doi: 10.1037/pap0000158

31. Perry JD, Perry JC. Conflicts, defenses and the stability of narcissistic personality features. Psychiatry Interpersonal Biol Processes. (2004) 67:31030. doi: $10.1521 /$ psyc.67.4.31056570

32. Hilsenroth MJ, Fowler JC, Padawer JR, Handler L. Narcissism in the Rorschach revisited: some reflections on empirical data. Psychol Assess. (1997) 9:113. doi: 10.1037/1040-3590.9.2113

33. Raskin R, Novacek J. Narcissism and the use of fantasy. $J$ Clin Psychol. (1991) 47:490-9. doi: $\quad 10.1002 / 1097-4679(199107) 47: 4<490:: A I D-J C L P 2270470404>3.0$ $\mathrm{CO} ; 2-\mathrm{J}$

34. Ronningstam E. Pathological narcissism and narcissistic personality disorder in Axis I disorders. Harvard Rev Psychiatry. (1996) 3:326-40. doi: 10.3109/10673229609017201

35. Ronningstam E. Narcissistic personality disorder: facing DSM-V. Psychiatric Ann. (2009) 39:9. doi: 10.3928/00485713-20090301-09

36. Pincus AL, Lukowitsky MR. Pathological narcissism and narcissistic personality disorder. Ann Rev Clin Psychol. (2010) 6:421-46. doi: 10.1146/annurev.clinpsy.1212081 31215

37. Miller JD, Lynam DR, McCain JL, Few LR, Crego C, Widiger TA, et al. Thinking structurally about narcissism: an examination of the Five-Factor Narcissism Inventory and its components. J Personal Disord. (2016) 30:1-18. doi: 10.1521/pedi_2015_29_177 
38. Crowe ML, Lynam DR, Campbell WK, Miller JD. Exploring the structure of narcissism: toward an integrated solution. J Personal. (2019) 87:1151-69. doi: $10.1111 /$ jopy12464

39. Houlcroft L, Bore M, Munro D. Three faces of narcissism. Personal Individ Differ. (2012) 53:274-8. doi: 10.1016/j.paid.2012.03036

40. Jauk E, Kaufman SB. The higher the score, the darker the core: the non-linear association between grandiose and vulnerable narcissism. Front Psychol. (2018) 9:1305. doi: 10.3389/fpsyg.201801305

41. Jauk E, Weigle E, Lehmann K, Benedek M, Neubauer AC. The relationship between grandiose and vulnerable (hypersensitive) narcissism. Front Psychol. (2017) 8:1600. doi: 10.3389/fpsyg.201701600

42. Kaufman SB, Weiss B, Miller JD, Campbell WK. Clinical correlates of vulnerable and grandiose narcissism: a personality perspective. J Personal Disord. (2020) 34:107-30. doi: 10.1521/pedi_2018_32_384

43. Miller JD, Hoffman BJ, Gaughan ET, Gentile B, Maples J, Keith Campbell W. Grandiose and vulnerable narcissism: a nomological network analysis. J Personal. (2011) 79:1013-42. doi: 10.1111/j.1467-6494.2010.00711x

44. Pincus AL, Ansell EB, Pimentel CA, Cain NM, Wright AG, Levy KN. Initial construction and validation of the Pathological Narcissism Inventory. J Personal Assess. (2009) 21:365. doi: 10.1037/a00 16530

45. Wink P. Two faces of narcissism. J Personal Soc Psychol. (1991) 61:590. doi: 10.1037/0022-3514.61.4590

46. Gore WL, Widiger TA. Fluctuation between grandiose and vulnerable narcissism. Personal Disord Theory Res Treat. (2016) 7:363. doi: $10.1037 /$ per0000181

47. Oltmanns JR, Widiger TA. Assessment of fluctuation between grandiose and vulnerable narcissism: development and initial validation of the FLUX scales. Psychol Assess. (2018) 30:1612. doi: 10.1037/pas0000616

48. Zajenkowski M, Witowska J, Maciantowicz O, Malesza M. Vulnerable past, grandiose present: the relationship between vulnerable and grandiose narcissism, time perspective and personality. Personal Individ Differ. (2016) 98:102-6. doi: 10.1016/j.paid.2016.03092

49. Rohmann E, Neumann E, Herner MJ, Bierhoff H-W. Grandiose and vulnerable narcissism. Eur Psychol. (2012) 17:279-90. doi: 10.1027/1016-9040/a000100

50. Besser A, Priel B. Grandiose narcissism versus vulnerable narcissism in threatening situations: emotional reactions to achievement failure and interpersonal rejection. J Soc Clin Psychol. (2010) 29:874-902. doi: 10.1521/jscp.2010.29.8874

51. Miller JD, Lynam DR, Vize C, Crowe M, Sleep C, Maples-Keller JL, et al. Vulnerable narcissism is (mostly) a disorder of neuroticism. J Personal. (2018) 86:186-99. doi: 10.1111/jopy12303

52. Erkoreka L, Navarro B. Vulnerable narcissism is associated with severity of depressive symptoms in dysthymic patients. Psychiatry Res. (2017) 257:2659. doi: 10.1016/j.psychres.2017.07061

53. Di Pierro R, Di Sarno M, Madeddu F. Investigating the relationship between narcissism and emotion regulation difficulties: the role of grandiose and vulnerable traits. Clin Neuropsychiatry. (2017) 14:20915. Available online at: https://www.semanticscholar.org/paper/ Investigating-the-relationship-between-narcissism-Pierro-Sarno/ 4d58898d0e23df171381f008241a424d9afd1a0c

54. Euler S, Stöbi D, Sowislo J, Ritzler F, Huber CG, Lang UE, et al. Grandiose and vulnerable narcissism in borderline personality disorder. Psychopathology. (2018) 51:110-21. doi: 10.1159/000486601

55. Dawood S, Pincus AL. Pathological narcissism and the severity, variability, and instability of depressive symptoms. Personal Disord Theory Res Treat. (2018) 9:144-54. doi: 10.1037/per0000239

56. Kealy D, Laverdière O, Pincus AL. Pathological narcissism and symptoms of major depressive disorder among psychiatric outpatients: the mediating role of impaired emotional processing. J Nerv Mental Dis. (2020) 208:161-4. doi: 10.1097/NMD0000000000001114

57. Marčinko D, Jakšić N, Ivezić E, Skočić M, Surányi Z, Lončar $M$, et al. Pathological narcissism and depressive symptoms in psychiatric outpatients: mediating role of dysfunctional attitudes. J Clin Psychol. (2014) 70:341-52. doi: $10.1002 /$ jclp22033
58. Almond R. I can do it (all) myself: clinical technique with defensive narcissistic self-sufficiency. Psychoanal Psychol. (2004) 21:371. doi: 10.1037/0736-9735.21.3371

59. Arikan K. A stigmatizating attitude towards psychiatric illnesses is associated with narcissistic personality traits. Israel J Psychiatry Relat Sci. (2005) 42:248. Available online at: https://www.semanticscholar. org/paper/AStigmatizatingAttitudeTowards-Psychiatric-is-Ar?kan/ aadd5cd265bcaeeaff77d9ce4fe16abf4ad39dc8?p2f

60. Cheek J, Kealy D, Joyce AS, Ogrodniczuk JS. Interpersonal problems associated with narcissism among psychiatric outpatients: a replication study. Archiv Psychiatry. (2018) 20:26-33. doi: 10.12740/APP/ 90328

61. Mielimaka M, Ogrodniczuk JS, Kealy D, Cheek J, Joyce AS. Narcissism and interpersonal problems among psychiatric outpatients: what is the role of defensive style? J Nerv Mental Dis. (2018) 206:711-5. doi: 10.1097/NMD0000000000000871

62. Fernie BA, Fung A, Nikčević AV. Different coping strategies amongst individuals with grandiose and vulnerable narcissistic traits. J Affect Disord. (2016) 205:301-5. doi: 10.1016/j.jad.2016.08009

63. Hansen-Brown AA, Freis SD. Assuming the worst: hostile attribution bias in vulnerable narcissists. Self Identity. (2021) 20:152-64. doi: 10.1080/15298868.20191609574

64. Krizan Z, Johar O. Narcissistic rage revisited. J Personal Soc Psychol. (2015) 108:784-801. doi: 10.1037/pspp0000013

65. Morf CC, Schürch E, Küfner A, Siegrist P, Vater A. Back M, et al. Expanding the nomological net of the Pathological Narcissism Inventory: German validation and extension in a clinical inpatient sample. Assessment. (2017) 24:419-43. doi: 10.1177/1073191115627010

66. Jakšić N, Milas G, Ivezić E, Wertag A, Jokić-Begić N, Pincus AL. The Pathological Narcissism Inventory (PNI) in transitional post-war Croatia: psychometric and cultural considerations. J Psychopathol Behav Assess. (2014) 36:640-52. doi: 10.1007/s10862-014-9425-2

67. Karakoula P, Triliva S, Tsaousis I. Description of the basic psychometric characteristics and the factor structure of the Greek version of the Pathological Narcissism Inventory. Psychology. (2013) 20:160-75. doi: 10.12681/psy_hps23534

68. Wright AG, Lukowitsky MR, Pincus AL, Conroy DE. The higher order factor structure and gender invariance of the Pathological Narcissism Inventory. Assessment. (2010) 17:467-83. doi: 10.1177/1073191110373227

69. Schauenburg H, Willenborg V, Sammet I, Ehrenthal JC. Self-reported defence mechanisms as an outcome measure in psychotherapy: a study on the German version of the Defence Style Questionnaire DSQ 40. Psychol Psychotherapy Theory Res Practice. (2007) 80:355-66. doi: 10.1348/147608306X146068

70. Andrews G, Singh M, Bond M. The defense style questionnaire. J Nerv Mental Dis. (1993) 181:246-56. doi: 10.1097/00005053-199304000-00006

71. Franke GH. Mini-SCL. German manual of the Mini Symptom Checklist [German]. Göttingen: Hogrefe. (2016).

72. Franke GH, Jaeger S, Glaesmer H, Barkmann C, Petrowski K, Braehler E. Psychometric analysis of the brief symptom inventory 18 (BSI-18) in a representative German sample. BMC Med Res Methodol. (2017) 17:14. doi: 10.1186/s12874-016-0283-3

73. Cramer P. Narcissism and attachment: the importance of early parenting. $J$ Nerv Mental Dis. (2019) 207:69-75. doi: 10.1097/NMD0000000000000919

74. Mikulincer M, Dolev T, Shaver PR. Attachment-related strategies during thought suppression: ironic rebounds and vulnerable self-representations. $J$ Personal Soc Psychol. (2004) 87:940. doi: 10.1037/0022-3514.87.6940

75. Faul F, Erdfelder E, Buchner A, Lang A-G. Statistical power analyses using G* Power 3.1: tests for correlation and regression analyses. Behav Res Methods. (2009) 41:1149-60. doi: 10.3758/BRM.41.41149

76. Kline RB. Principles and Practice of Structural Equation Modeling (3. Baski). New York, NY: Guilford. (2011).

77. Eid M. Multi-faceted constructs in abnormal psychology: implications of the bifactor S-1 model for individual clinical assessment. J Abnormal Child Psychol. (2020) 48:895-900. doi: 10.1007/s10802-02000624-9 
78. Eid M, Geiser C, Koch T, Heene M. Anomalous results in G-factor models: explanations and alternatives. Psychol Methods. (2017) 22:541. doi: $10.1037 /$ met0000083

79. Schermelleh-Engel K, Moosbrugger H, Müller H. Evaluating the fit of structural equation models: tests of significance and descriptive goodnessof-fit measures. Methods Psychol Res. (2003) 8:23-74. Available online at: http://citeseerx.ist.psu.edu/viewdoc/download?doi=10.1.1.509.4258\&rep= rep1\&type $=$ pdf

80. Zeigler-Hill V, Besser A. Humor style mediates the association between pathological narcissism and self-esteem. Personal Individ Differ. (2011) 50:1196-201. doi: 10.1016/j.paid.2011.02006

81. Richardson EN, Boag S. Offensive defenses: the mind beneath the mask of the dark triad traits. Personal Individ Differ. (2016) 92:148-52. doi: 10.1016/j.paid.2015.12039

82. Khodabakhsh Pirklany R, Safaeian E. Comparing the Defense styles and the Self-conscious affect of Shame and Guilt in subtypes of Narcissism and comparison with ordinary people. J Psychol Stud. (2020) 15:7-24. doi: 10.22051/PSY.2020.23089.1820

83. Ng HK, Cheung RY-H, Tam K-P. Unraveling the link between narcissism and psychological health: new evidence from coping flexibility. Personal Individ Differ. (2014) 70:7-10. doi: 10.1016/j.paid.2014.06006

84. Zhang $\mathrm{H}$, Luo $\mathrm{Y}$, Zhao $\mathrm{Y}$, Zhang R, Wang Z. Differential relations of grandiose narcissism and vulnerable narcissism to emotion dysregulation: self-esteem matters. Asian J Soc Psychol. (2017) 20:232-7. doi: 10.1111/ajsp12191

85. Zimmermann J, Kerber A, Rek K, Hopwood CJ, Krueger RF. A brief but comprehensive review of research on the Alternative DSM5 model for personality disorders. Curr Psychiatry Rep. (2019) 21:1-19. doi: 10.1007/s11920-019-1079-z

86. Bender DS, Morey LC, Skodol AE. Toward a model for assessing level of personality functioning in DSM-5, Part I: a review of theory and methods. $J$ Personal Assess. (2011) 93:332-46. doi: 10.1080/00223891.2011583808

87. Hopwood CJ, Kotov R, Krueger RF, Watson D, Widiger TA, Althoff RR, et al. The time has come for dimensional personality disorder diagnosis. Personal Mental Health. (2018) 12:82. doi: 10.1002/pmh1408

88. Widiger TA, Sellbom M, Chmielewski M, Clark LA, DeYoung CG, Kotov R, et al. Personality in a hierarchical model of psychopathology. Clin Psychol Sci. (2019) 7:77-92. doi: 10.1177/2167702618797105

89. Kampe L, Zimmermann J, Bender D, Caligor E, Borowski A-L, Ehrenthal JC, et al. Comparison of the structured DSM-5 clinical interview for the Level of Personality Functioning Scale with the Structured Interview of Personality Organization. J Personal Assess. (2018) 100:642-9. doi: 10.1080/00223891.20181489257

90. Kampe L. Zum Paradigmenwechsel der Diagnostik der Persönlichkeitsstörungen. Gegenüberstellung des STIPO-Interviews mit dem Interview der LPFS des DSM-5. Hamburg: Verlag Dr. Kovac. (2019).

91. Clarkin JF, Caligor E, Stern BL, Kernberg OF. Structured Interview of Personality Organization. New York, NY: STIPO. (2004).

92. Day N, Townsend ML, Grenyer B. Living with pathological narcissism: a qualitative study. Borderline Personal Disord Emotion Dysregul. (2020) 7:1-14. doi: 10.1186/s40479-020-00132-8

93. Barr KR, Jewell M, Townsend ML, Greyner BFS. Living with personality disorder and seeking mental health treatment: patients and family members reflect on their experiences. Borderline Personal Disord Emotion Dysregul. (2020) 7:4. doi: 10.1186/s40479-020-00136-4

94. Ellison WD, Acuff MC, Kealy D, Joyce AS, Ogrodniczuk JS. Narcissism and quality of life: the mediating role of relationship patterns. J Nerv Mental Dis. (2020) 208:613-8. doi: 10.1097/NMD0000000000001170

95. Kramer U, Pascual-Leone A, Rohde KB, Sachse R. The role of shame and self-compassion in psychotherapy for narcissistic personality disorder: an exploratory study. Clin Psychol Psychotherapy. (2018) 25:272-82. doi: $10.1002 /$ cpp 2160

96. Kealy D, Goodman G, Rasmussen B, Weideman R, Ogrodniczuk JS. Therapists' perspectives on optimal treatment for pathological narcissism. Personal Disord. (2017) 8:35-45. doi: 10.1037/per0000164

97. Dickinson KA, Pincus AL. Interpersonal analysis of grandiose and vulnerable narcissism. J Personal Disord. (2003) 17:188-207. doi: 10.1521 /pedi.17.3.18822146
98. Clarkin J, Kernberg O, Yeomans F. Transference-Focused Psychotherapy for Borderline Personality Disorder Patients. New York, NY: Guilford. (1999)

99. Diamond D, Clarkin JF, Levy KN, Meehan KB, Cain NM, Yeomans $\mathrm{FE}$, et al. Change in attachment and reflective function in borderline patients with and without comorbid narcissistic personality disorder in transference focused psychotherapy. Contemp Psychoanal. (2014) 50:175210. doi: 10.1080/00107530.2014880316

100. Stern BL, Yeomans F, Diamond D, Kernberg OF. Transferencefocused psychotherapy for narcissistic personality. J Pers Disord. (2013) 34(Suppl.):159-76. doi: 10.1037/14041-014

101. Buchheim A, Hörz-Sagstetter S, Doering S, Rentrop M, Schuster P, Buchheim $\mathrm{P}$, et al. Change of unresolved attachment in borderline personality disorder: RCT study of transference-focused psychotherapy. Psychotherapy Psychosomatics. (2017) 86:314-6. doi: 10.1159/0004 60257

102. Clarkin JF, Cain NM, Lenzenweger MF. Advances in transference-focused psychotherapy derived from the study of borderline personality disorder: clinical insights with a focus on mechanism. Curr Opin Psychol. (2018) 21:80-5. doi: 10.1016/j.copsyc.2017.09008

103. Doering S, Hörz S, Rentrop M, Fischer-Kern M, Schuster P, Benecke C, et al. Transference-focused psychotherapy v. treatment by community psychotherapists for borderline personality disorder: randomised controlled trial. Br J Psychiatry. (2010) 196:389-95. doi: 10.1192/bjp.bp.1090 70177

104. Fischer-Kern M, Doering S, Taubner S, Hörz S, Zimmermann J, Rentrop $\mathrm{M}$, et al. Transference-focused psychotherapy for borderline personality disorder: change in reflective function. Br J Psychiatry. (2015) 207:173-4. doi: 10.1192/bjp.bp.113143842

105. Perez DL, Vago DR, Pan H, Root J, Tuescher O, Fuchs BH, et al. Frontolimbic neural circuit changes in emotional processing and inhibitory control associated with clinical improvement following transference-focused psychotherapy in borderline personality disorder. Psychiatry Clin Neurosci. (2016) 70:51-61. doi: 10.1111/pcn 12357

106. Tmej A, Fischer-Kern M, Doering S, Hörz-Sagstetter S, Rentrop M, Buchheim A. Borderline patients before and after 1 year of transference-focused psychotherapy (TFP): a detailed analysis of change of attachment representations. Psychoanal Psychol. (2020) 38:12-21. doi: 10.1037/pap0000302

107. Sheppes G, Suri G, Gross JJ. Emotion regulation and psychopathology. Ann Rev Clin Psychol. (2015) 11:379-405. doi: 10.1146/annurev-clinpsy-032814-112739

108. Koole SL, Rothermund K. "I feel better but I don't know why": the psychology of implicit emotion regulation. Cogn Emotion. (2011) 25:389-99. doi: 10.1080/02699931.2010550505

109. Cone J, Mann T, Ferguson M. Can we change our implicit minds? New evidence for how, when, and why implicit impressions can be rapidly revised. Adv Soc Psychol. (2017) 56:131-99. doi: 10.1016/bs.aesp.2017. 03001

110. Greenwald AG, Lai CK. Implicit social cognition. Ann Rev Psychol. (2020) 71:50837. doi: 10.1146/annurev-psych-010419-050837

111. Cramer P. Defense mechanisms: 40 years of empirical research. J Pers Assess. (2015) 97:114-22. doi: 10.1080/00223891.2014. 947997

112. Hansen-Brown AA, Freis SD. Assuming the worst: Hostile attribution bias in vulnerable narcissists. Self Identity. (2019) 20:152-64. doi: 10.1080/15298868.2019.1609574

Conflict of Interest: The authors declare that the research was conducted in the absence of any commercial or financial relationships that could be construed as a potential conflict of interest.

Copyright (c) 2021 Kampe, Bohn, Remmers and Hörz-Sagstetter. This is an openaccess article distributed under the terms of the Creative Commons Attribution License (CC BY). The use, distribution or reproduction in other forums is permitted, provided the original author(s) and the copyright owner(s) are credited and that the original publication in this journal is cited, in accordance with accepted academic practice. No use, distribution or reproduction is permitted which does not comply with these terms. 


\section{APPENDIX}

Table A1 | Model Fit Indices of all 20 structural equation models.

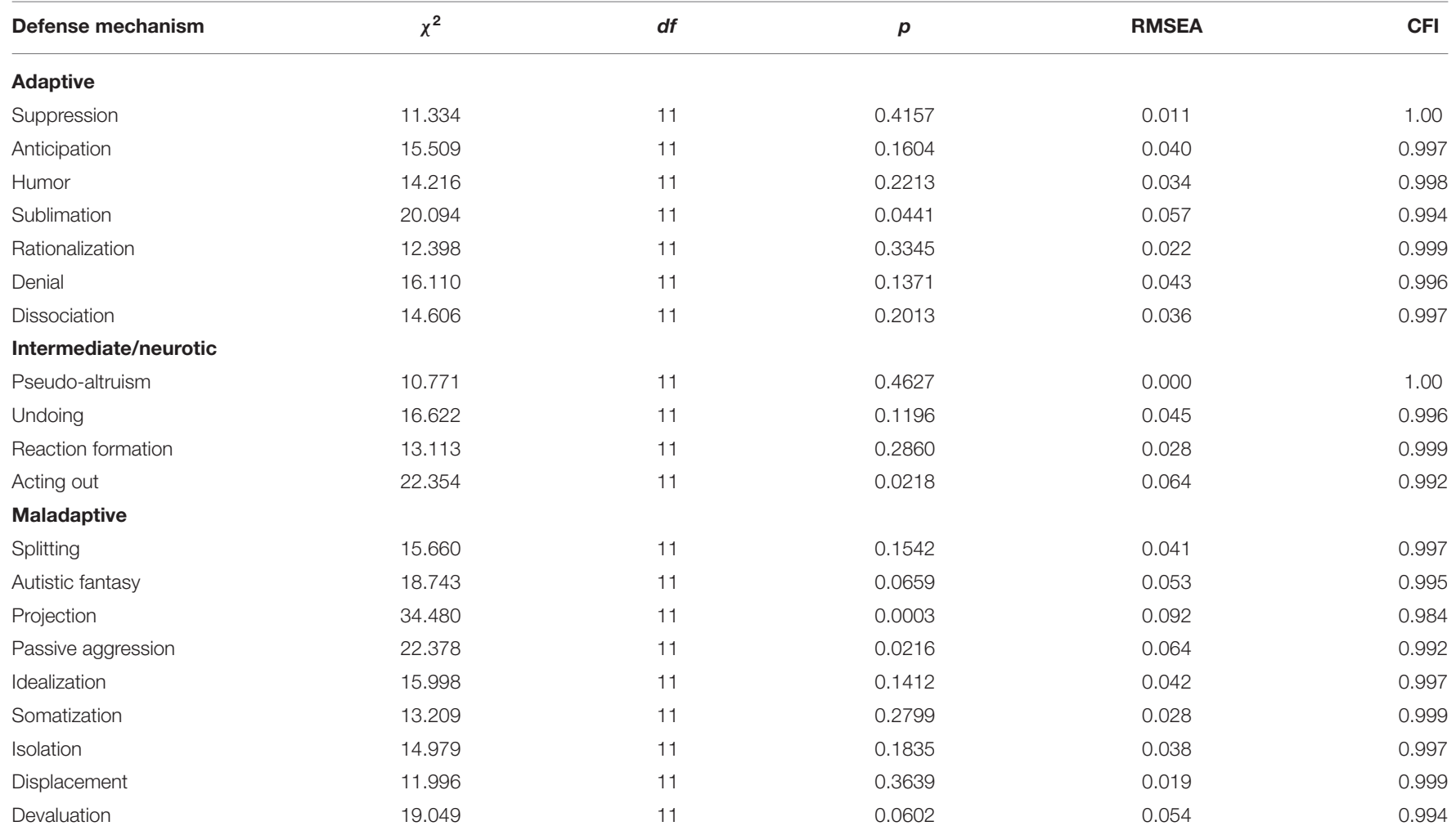

The 20 models differ in the defense mechanism.

RMSEA $=$ Root Mean Square Error of Approximation; CFI = Comparative Fit Index . 